\title{
MODELING OPTIMISM AND PESSIMISM IN THE FOREIGN EXCHANGE MARKET
}

\author{
PAUL DE GRAUWE \\ PABLO ROVIRA KALTWASSER
}

CESIFO WORKING PAPER NO. 1962

Category 6: Monetary Policy And International Finance

APRIL 2007

Presented at CESifo Area Conference on Macro, Money

\& INTERNATIONAL FinANCE, FEBRUARY 2007

An electronic version of the paper may be downloaded

- from the SSRN website:

- from the RePEc website:

www.SSRN.com

- from the CESifo website:

www.RePEc.org

www.CESifo-group.de 


\title{
MOdeling OPTIMISM AND PESSIMISM IN THE FOREIGN EXCHANGE MARKET
}

\begin{abstract}
In this paper we model how the existence of different beliefs about the underlying fundamental value of a currency affects the dynamics of the exchange rate. We find that a divergence of beliefs creates the potential for waves of optimism and pessimism that alternate in an unpredictable way. These waves are disconnected from the underlying (objective) fundamental value. We also find that in such a world there is "sensitivity to initial conditions", i.e. small changes in beliefs can fundamentally alter the time path of the exchange rate.
\end{abstract}

JEL Code: C63, G12, G15.

\author{
Paul De Grauwe \\ University of Leuven \\ Department of Economics \\ Naamsestraat 69 \\ 3000 Leuven \\ Belgium \\ paul.degrauwe@econ.kuleuven.be
}

\author{
Pablo Rovira Kaltwasser \\ University of Leuven \\ Department of Economics \\ Naamsestraat 69 \\ 3000 Leuven \\ Belgium \\ pablo.rovirakaltwasser@econ.kuleuven.be
}

This Draft: March 19, 2007

We thank Jakob de Haan, Geert Dhaene, Hans Dewachter, Gerben de Zwart, Cars Hommes, Gerhard Illing, Pelin Ilbas, Georg Kirchsteiger, Thomas Lux, Marc Muendler, Kristien Smedts, Philippe Weil and Frank Westermann and several other participants of the CESifo Area Conference on Macro Money and Finance (Munich), the Conference on Heterogeneous Agents in Financial Markets (Nijmegen) and of several seminar presentations for their valuable comments. We are also indebted to the Research Foundation - Flanders (FWO) for financial support. 


\section{Introduction}

Beliefs are important forces, not only in everyday life, but also in financial markets. Changes in beliefs shape events even if there is no change in the objective forces affecting reality. This has long been recognized by economists in the past. Keynes (1936), for example, wrote about "animal spirits" influencing reality and creating waves of optimism and pessimism. In his celebrated study, "Manias, panics and crashes" Kindleberger analyzed the way agents develop beliefs and how these beliefs move stock prices.

In recent years two sets of beliefs have emerged about the fundamental value of the U.S. dollar. The first set has been represented, among others, by Obstfeld and Rogoff (2005) and Obstfeld (2005). According to this view the large current account deficits of the U.S. observed in the last years are unsustainable. A major decline in the value of the dollar will be the consequence of adjusting the current account balance to a sustainable level. These authors have estimated that restoring the balance in U.S., European and Asian current accounts would imply a 30 percent depreciation of the dollar against the Euro and a 35 percent depreciation against a basket of Asian currencies respectively. There is another belief about the fundamental value of the dollar, though, that offers a contrarian view to the one sketched above, e.g. Hausmann and Sturzenegger (2006). In this alternative view there does not arise a problem of sustainability. The reason behind this divergent views lies in a concept that the authors call "Dark Matter", i.e. attributes present in certain assets (the U.S. dollar in this case) that can not properly be measured. Corrected for the amount of "dark matter" these authors come to the conclusion that there is in fact no net foreign US debt.

It is not our objective here to judge whether one view or the other is correct. There can be little doubt, however, that these opposing beliefs about the fundamental value of the dollar are realities that can affect the dollar exchange rate. The rational expectations (RE) paradigm has tended to drive the analysis of these phenomena out of existence. After all in a world where agents (i.e. a representative agent) are assumed to understand the complexity of the world in which they live, there is no room for different beliefs that systematically diverge from the underlying objective reality. Beliefs are part of the irrational world. These may be the subject of psychological analysis, not of economic analysis.

In this paper we develop a systematic analysis of beliefs in the foreign exchange market. 
We depart from the rational expectations assumption. The fact that we depart from rational expectations, however, does not imply that we move into a world of irrationality, a world about which the economist has little to say. The rational expectations paradigm lays an undue claim on the label "rational". The use of this label implies that departures from the RE-paradigm involve irrational behavior. But this is not necessarily true. The label "rational" in the RE-paradigm refers to an informational assumption, i.e. that agents use the same information as the one underlying the model in which they operate. Even though this sounds reasonable, it has the important implication that agents in the RE-paradigm have a full understanding about how the model functions, whatever the complexity of the model. There is now a significant body of evidence from psychology and brain science that agents experience cognitive problems in understanding the world in which they live; they find it hard to process the information they face and to make sense of it. As a result, a large number of new modelling approaches that explicitly take into account these cognitive limitations have emerged (Frankel and Froot (1998), Brock and Hommes (1998), Lux and Marchesi (1999), Brunnemeier (2001), Kirmann and Theyssière (2002), De Grauwe and Grimaldi (2006), Lux and Schornstein (2005)).

These new insights should be used in economics. The need to do so is all the stronger as the RE-paradigm performs very poorly in empirical testing. We intend to show that these new insights can be used without throwing away the notion of rationality. Agents in our model will continue to be utility maximizing agents. We will assume, however, that they do not understand the underlying model fully. Therefore they use simple rules and develop divergent beliefs about the workings of the model. We discipline the use of these rules by imposing a selection mechanism whereby only the most useful (profitable) rules and beliefs are maintained. Thus agents are rational in that they continuously search for the best rule and the best belief, letting relative risk adjusted profitability do the job of weeding out the bad ones. In this sense our modeling approach is immune to the often heard criticism against the modeling of expectations outside the rational expectations framework, i.e. that in the non-RE approach "anything can happen". Profit based selection of rules impose the necessary discipline ensuring that not "anything can happen".

The remaining of the paper is organized as follows. In section 2 we present the theoretical model. Section 3 shows stochastic simulations of the model. In sections 4 and 5 we 
show the results from sensitivity analysis in a deterministic and a stochastic environment respectively. In section 6 we analyze the relevance of changes in beliefs in a stochastic framework. In section 7 we study the relevance of divergent beliefs on the volatility of the exchange rate. Finally, section 8 concludes.

\section{Theoretical exchange rate model}

In this section we present the model. It is an extension of the model in De Grauwe \& Grimaldi (2006). In that model we assumed that the fundamentalists know the fundamental value of the exchange rate with certainty. Here we depart from that assumption. We assume that there are differences of opinion (different beliefs) about the true fundamental. One belief is an optimistic one, i.e. it is one in which the fundamental value is systematically overestimated; the other is a pessimistic one, i.e. it is one in which the fundamental is systematically underestimated. Agents using a fundamentalist rule to forecast the exchange rate choose one of these two beliefs and stick to it as long as it is more profitable than the alternative ${ }^{1}$.

\subsection{The optimal portfolio}

We assume agents of different types $i$ depending on their beliefs about the future exchange rate. Each agent can invest in two assets, a domestic (risk-free) asset and foreign (risky) assets. The agents' utility function can be represented by the following equation:

$$
U\left(W_{t+1}^{i}\right)=E_{t}^{i}\left(W_{t+1}^{i}\right)-\frac{1}{2} \mu V^{i}\left(W_{t+1}^{i}\right)
$$

where $W_{t+1}^{i}$ is the wealth of an agent using rule of type $i$ to forecast the exchange rate for period $t+1, E_{t}^{i}$ is the expectation operator, $\mu$ is the coefficient of risk aversion and $V^{i}\left(W_{t+1}^{i}\right)$ represents the conditional variance of wealth of agent using rule $i^{2}$ The wealth dynamics is governed by:

$$
W_{t+1}^{i}=\left(1+r^{*}\right) s_{t+1} d_{t}^{i}+(1+r)\left(W_{t}^{i}-s_{t} d_{t}^{i}\right)
$$

where $r$ and $r^{*}$ are respectively the domestic and the foreign interest rates (which are known with certainty), $s_{t+1}$ is the exchange rate at time $t+1, d_{i, t}$ represents the holdings

\footnotetext{
${ }^{1}$ Corrado, et al. (2007) use a similar setup assuming the existence of "bears" and "bulls". Our model differs from theirs in the way agents choose to be bulls or bears. As will be seen, in our model bears and bulls can coexist, which is not the case in Corrado, et al. (2007).

${ }^{2}$ The functional form of the different forecasting rules will be specified in the next section.
} 
of the foreign assets by agent using rule type $i$ at time $t$. Thus, the first term on the righthand side of equation 2 represents the value of the (risky) foreign portfolio expressed in domestic currency at time $t+1$ while the second term represents the value of the (riskless) domestic portfolio at time $t+1 .^{3}$

Substituting equation 2 in 1 and maximizing the utility with respect to $d_{i, t}$ allows us to derive the standard optimal holding of foreign assets by agents using a forecasting rule of type $i:^{4}$

$$
d_{i, t}=\frac{\left(1+r^{*}\right) E_{t}^{i}\left[s_{t+1}\right]-(1+r) s_{t}}{\mu \sigma_{i, t}^{2}}
$$

where $\sigma_{i, t}^{2}=\left(1+r^{*}\right)^{2} V_{t}^{i}\left(s_{t+1}\right)$. The optimal holding of the foreign asset depends on the expected excess return (corrected for risk) of the foreign asset. The market demand for foreign assets at time $t$ is the sum of the individual demands, i.e.:

$$
\sum_{i=1}^{I} n_{i, t} d_{i, t}=D_{t}
$$

where $n_{i, t}$ is the number of agents using rule of type $i$ at period $t$.

Market equilibrium implies that the market demand is equal to the market supply $Z_{t}$ which we assume to be exogenous. ${ }^{5}$ Thus,

$$
Z_{t}=D_{t}
$$

Substituting the optimal holdings into the market demand and then into the market equilibrium equation and solving for the exchange rate $s_{t}$ yields the market clearing exchange rate:

$$
s_{t}=\left(\frac{1+r^{*}}{1+r}\right) \frac{1}{\sum_{i=1}^{I} \frac{w_{i, t}}{\sigma_{i, t}}}\left[\sum_{i=1}^{I} w_{i, t} \frac{E_{t}^{i}\left[s_{t+1}\right]}{\sigma_{i, t}^{2}}-\Omega_{t} Z_{t}\right]+\varepsilon_{t}
$$

where $w_{i, t}=\frac{n_{i, t}}{\sum_{i=1}^{I} n_{i, t}}$ is the weight (share) of agent using rule type $i, \Omega_{t}=\frac{\mu}{\left(1+r^{*}\right) \sum_{i=1}^{I} n_{i, t}}$ and $\varepsilon \geq_{t}$ is an $I I D$ normally distributed shock to $s_{t}$ with mean zero and variance $\sigma_{\varepsilon}^{2}$.

\footnotetext{
${ }^{3}$ The model could be interpreted as an asset pricing model with one risky asset (e.g. shares) and a risk free asset. Equation (2) would then be written as

$W_{t+1}^{i}=\left(s_{t+1}+y_{t+1}\right) d_{t}^{i}+(1+r)\left(W_{t}^{i}-s_{t} d_{t}^{i}\right)$

where $s_{t+1}$ is the price of the share in $\mathrm{t}+1$ and $y_{t+1}$ is the dividend per share in $\mathrm{t}+1$.

${ }^{4}$ If the model is interpreted as an asset pricing model of one risky asset (shares) and a risk free asset, the corresponding optimal holding of the risky asset becomes

$$
d_{i, t}=\frac{E_{t}^{i}\left(s_{t+1}+y_{t+1}\right)-(1+r) s_{t}}{\mu \sigma_{i, t}^{2}}
$$

${ }^{5}$ The market supply is determined by the net current account and by the sales or purchases of foreign exchange of the central bank. We assume both to be exogenous here. In De Grauwe and Grimaldi 2006 a model with endogenized current account is presented.
} 
Thus the market clearing exchange rate is determined by the forecasts of the agents, $E_{t}^{i}$, about the future exchange rate. Note also that the forecasts are weighted by their respective variances $\sigma_{i, t}^{2}$. When agent's $i$ forecasts have a high variance the weight of this agent in the determination of the market exchange rate is reduced. In the following we will set $r=r^{*}$.

\section{$2.2 \quad$ Forecasting rules}

Agents can choose between two different types of rules to forecast the exchange rate, a fundamentalist and a chartist (extrapolative) rule. In addition, we assume an optimistic and a pessimistic fundamentalist rule. As a result, there are three rules to choose from.

Fundamentalists ${ }^{6}$ make their forecasts by comparing last period's market exchange rate with their belief about last period's fundamental exchange rate. Agents using a fundamentalist rule adhere to either the optimistic of the pessimistic belief. The forecasting rule for fundamentalists is therefore given by:

$$
E_{t}^{o p t}\left[\Delta s_{t+1}\right]=-\psi\left(s_{t-1}-s_{o p t, t-1}^{*}\right)
$$

and

$$
E_{t}^{\text {pes }}\left[\Delta s_{t+1}\right]=-\psi\left(s_{t-1}-s_{p e s, t-1}^{*}\right)
$$

where $s_{o p t, t-1}^{*}$ is the optimistic estimate of the fundamental exchange rate in period $t-1, s_{\text {pes,t-1 }}^{*}$ is the pessimistic estimate of the fundamental exchange rate $t-1$, and $0<\psi<1$. We assume the optimistic and pessimistic beliefs of agents to be given by:

$$
s_{o p t, t-1}^{*}=s_{t-1}^{*}+a
$$

and

$$
s_{p e s, t-1}^{*}=s_{t-1}^{*}-a
$$

where $a>0$ and $s_{t-1}^{*}$ is the true, unobserved fundamental exchange rate. Thus the optimists overestimate the true fundamental by a constant $a$ and the pessimists underestimate it by the same constant. Notice that even though agents using a fundamentalist rule have heterogeneous estimates of the value of the fundamental exchange rate, they use

\footnotetext{
${ }^{6}$ We use the term "fundamentalist" in a loose sense. It is an agent who chooses to use a fundamentalist forecasting rule.
} 
a mean reverting rule to forecast the exchange rate. Put differently, if for instance agent $i$ using an optimistic fundamentalist rule observes that the market exchange rate exceeds (is below) her estimate of the fundamental, $s_{f^{o p t}, t-1}^{*}$, she will expect the market exchange rate to decline (increase) towards the "fundamental" next period. The same occurs when the agent uses the pessimistic belief about the fundamental exchange rate. The parameter $\psi$ expresses the percentage of the estimated misalignment (i.e. $s_{t-1}-s_{o p t, t-1}^{*}, s_{t-1}-s_{p e s, t-1}^{*}$ ) expected to be corrected next period. The change in the value fundamental exchange rate in our model can be seen as an exogenous news arrival dynamic process. We assume that this news arrival process is $I I D$ normally distributed process, i.e. $s_{t}^{*}-s_{t-1}^{*}=\xi_{t}$

where $\xi_{t}$ is white noise with mean 0 and variance $\sigma_{\xi}^{2}$. Notice that we have chosen an overly simple formulae to model the degree of optimism-pessimism bias. The advantage of adding a constant to the level of the (unobserved) fundamental exchange rate is that it does not affect the dynamic properties of the news arrival process. As a consequence, if any degree of non-linear dependence in the market exchange rate series is observed, it cannot be attributed to the law of motion of both the unobserved fundamental exchange rate or of the beliefs about it. By setting parameter $a$ equal to zero we will analyze whether we are able find non-linear dependence in the market exchange rate series generate by the model in the absence of optimism-pessimism bias. Letting parameter $a$ vary will allow us to get an intuition of the implications for the statistical properties of the market exchange rate of having a systematic bias in the beliefs about the underlying fundamental. ${ }^{7}$

The chartist forecasting rule is extrapolative, i.e. agents using such a rule extrapolate past changes of the exchange rate into the future. Formally:

$$
E_{t}^{c}\left[\Delta s_{t+1}\right]=\beta \Delta s_{t-1}
$$

where $\beta>0$ is the extrapolating parameter expressing the extent to which past changes are extrapolated into the future.

Finally, equation 6 also depends on the risk of investing in the foreign portfolio. Risk is defined as the variance of the one period ahead forecast errors made by the agents. Since agents make different forecasts, the risks involved differ. We obtain the following

\footnotetext{
${ }^{7}$ To check for robustness of our empirical results we also allowed the fundamental exchange rate to follow a autoregressive stationary process. Since the results under both definitions of the fundamental were not different we decided to maintain our original assumption of a random walk process driving the fundamental.
} 
expressions: ${ }^{8}$

$$
\begin{aligned}
\sigma_{o p t, t+1}^{2} & =\left(E_{t}^{o p t}\left[s_{t+1}\right]-s_{t+1}\right)^{2} \\
\sigma_{f p e s, t+1}^{2} & =\left(E_{t}^{p e s}\left[s_{t+1}\right]-s_{t+1}\right)^{2} \\
\sigma_{c, t+1}^{2} & =\left(E_{t}^{c}\left[s_{t+1}\right]-s_{t+1}\right)^{2}
\end{aligned}
$$

\subsubsection{Fitness of the rules}

The next step in our analysis is to specify how agents evaluate their forecasting rules. The general idea that we follow here is that agents choose one of the available rules, then compare ex post the (risk adjusted) returns of the rule they have used with the alternatives, after which they decide whether to keep the rule or to switch to another one. Thus, our model is in the logic of evolutionary dynamics. Agents make a choice ex-ante. Once the outcome of their choice is observable they evaluate their decision. They do this by comparing how profitable their choice has been compared to alternative choices. When they find out that the rule they have chosen is not as profitable as the alternatives, they revise their decisions and change the forecasting rule by a more profitable one in order to maximize the return of their portfolio. Thus the rules are subjected to a "fitness" test.

In order to implement this idea we use the approach proposed by Brock and Hommes (1997) which consists in making the weights of the forecasting rules a function of the relative (risk adjusted) return of these rules, i.e.: ${ }^{9}$

$$
\begin{aligned}
w_{o p t, t} & =\frac{\exp \left[\gamma \pi_{o p t, t}^{\prime}\right]}{\sum_{i=1}^{4}\left(\exp \left[\gamma \pi_{i, t}^{\prime}\right]\right)} \\
w_{p e s, t} & =\frac{\exp \left[\gamma \pi_{p e s, t}^{\prime}\right]}{\sum_{i=1}^{4}\left(\exp \left[\gamma \pi_{i, t}^{\prime}\right]\right)}
\end{aligned}
$$

\footnotetext{
${ }^{8}$ Here we implicitly assume that agents remember only the risk associated with the last period's decision. A memory parameter can be easily added in order to allow agents to have a longer memory horizon. In De Grauwe and Grimaldi (2006), for instance, agents' memory is the weighted average of all past variances and the weights are assumed to decay exponentially, i.e. agents attach a higher weight to recent mistakes and lower weight to mistakes that lie further in the past.

${ }^{9}$ This specification of the decision rule is often used in discrete choice models. For an application in the market for differentiated products see Anderson, de Palma, and Thisse (1992). The idea has also been applied in financial markets, by Brock and Hommes (1997), by Lux 1998) and by Lux and Marchesi (1999).
} 


$$
w_{c, t}=\frac{\exp \left[\gamma \pi_{c, t}^{\prime}\right]}{\sum_{i=1}^{4}\left(\exp \left[\gamma \pi_{i, t}^{\prime}\right]\right)}
$$

where $\pi_{o p t, t}^{\prime}, \pi_{p e s, t}^{\prime}$ and $\pi_{c, t}^{\prime}$ are the risk adjusted net returns made by the use of the different forecasting rules. Note that $\pi_{o p t, t}^{\prime}=\pi_{o p t, t}-\mu \sigma_{o p t, t}^{2}, \pi_{p e s, t}^{\prime}=\pi_{p e s, t}-\mu \sigma_{p e s, t}^{2}$. and $\pi_{c, t}^{\prime}=\pi_{c, t}-\mu \sigma_{c, t}^{2}$.

Equations 15, 16 and 17 can be interpreted as switching rules. When the risk adjusted return of a particular rule increases relative to the risk adjusted return obtained from the other rules (the denominator), then the share of agents who use that rule increases, and vice versa. Notice that the switches between forecasting rules are governed by a time-varying and endogenous mechanism. The motivation to use such a switching mechanism is the following: agents observe their environment and react to economic variables by adjusting their behavior with a certain probability that is a function of those economics variables. In our model, the economic variable that drives these changes in agents' behavior is the ex-post (risk-adjusted) return of their investment in the foreign exchange market. The parameter $\gamma$ measures the intensity with which agents revise their forecasting rules. With an increasing $\gamma$ agents react strongly to the relative return of the rules. In the limit when $\gamma$ goes to infinity all agents choose the forecasting rule which proves to be the most profitable. When $\gamma$ is equal to zero agents are insensitive to the relative return of the rules. Thus, $\gamma$ is a measure of inertia in the decision to switch to the more profitable rule. ${ }^{10}$ As will be seen, this parameter is of great importance in generating bubbles.

We define the return as the one-period returns of investing $1 \$$ in the foreign asset. More formally,

$$
\begin{gathered}
\pi_{i, t}=\left[s_{t}\left(1+r^{*}\right)-s_{t-1}(1+r)\right] \operatorname{sgn}\left[\left(1+r^{*}\right) E_{t-1}^{i}\left[s_{t}\right]-(1+r) s_{t-1}\right] \\
\text { where } \operatorname{sgn}[x]=\left\{\begin{array}{cl}
1 & \text { for } x>0 \\
0 & \text { for } x=0 \\
-1 & \text { for } x<0
\end{array} \text { and } i=\text { opt,pes, } c\right.
\end{gathered}
$$

Thus, when agents forecasted an increase in the exchange rate and this increase is realized, their per unit profit is equal to the observed increase in the exchange rate (corrected for the interest differential). If instead the exchange rate declines, they make a per

\footnotetext{
${ }^{10}$ The psychological literature reveals that there is a lot of evidence of a "status quo bias" in decision making (see Kahneman, Knetsch and Thaler (1991). This implies $\gamma<\infty$. Thus we set $0<\gamma<\infty$.
} 
unit loss which equals this decline (because in this case they have bought foreign assets which have declined in price).

We use a concept of return instead of profits for two reasons. First, our switching rules of equations 16, 15 and 17 selects the fittest rules. It does not select agents. Second, in our definition of returns agents only have to use publicly available information, i.e. the forecasting rules and the observed exchange rate changes. They do not have to know their competitor's profits. Furthermore, the profit obtained by taking a certain position are a function of the amount invested which is not of public knowledge in our model. Here we assume that every agent invests only $\$ 1$ and therefore the profits are to be interpreted as the percentage return obtained by taking a particular position.

\section{Stochastic simulation of the model}

Due to the strong nonlinearities of the model it is not possible to characterize its equilibrium and its dynamics in an analytical way. That is why we use numerical methods to do so. We first present the results of simulating the model in the time domain. We use the following set of parameter values that we consider to be the benchmark case: $\sigma_{\varepsilon}^{2}=0.1$, $\sigma_{\varepsilon}^{2}=0.1, a=4, \psi=0.2$ and $\beta=0.9$. We will then compare the results of this benchmark case to other parameter values. After presenting the benchmark case we will allow for different levels of divergence in beliefs. In the next section we will analyze the importance of other parameters of the model. The results of the benchmark case are shown in figure 1. The upper panel of figure 1 shows the simulated market exchange rate and the optimistic and pessimistic beliefs of the fundamentalists. The lower panel shows the weights of the optimistic and pessimistic fundamentalists. (Note that the weight of the chartists $\left[1-\left(w_{\text {opt }}+w_{\text {pes }}\right)\right]$ is not shown). Figure 1 leads to the following observations. First, there appear to be three different regimes in the exchange rate dynamics. There are periods during which the exchange rate fluctuates around the optimistic estimate of the fundamental, and periods during which it fluctuates around the pessimistic estimate. During the optimistic regime we observe from the lower panel that the weights of the optimistic fundamentalists are positive, while the weights of the pessimists are close to zero. During the pessimistic regime we observe the opposite. There is also a third regime: this is when the exchange rate wanders away from the both perceived fundamentals. In the lower panel we see that in this regime the weights of both fundamentalists are close 
to zero which implies that the weight of the chartists is close to 1 . Thus our model generates endogenous waves of optimism and pessimism as well as bubbles in the foreign exchange market. These waves come and go in an unpredictable way. We could not find any regularity in the cyclical movements of optimism and pessimism. Once in a while, and equally unpredictably, the exchange rate wanders away from the fundamentals. We call this regime a non-fundamental (bubble) regime. In section we will present results that allow us to be more precise about these different regimes and their occurrence.

We next analyze how the divergence of opinion among fundamentalists affects the results. We now simulate the model for two alternative values of $a$, i.e. $a=2$ (weak divergence of opinion) and $a=6$ (strong diversion of opinion). We show the results in figures $2 \mathrm{a}$ (weak divergence) and $2 \mathrm{~b}$ (strong divergence). The differences are striking. When divergence of opinion is weak we cannot clearly demarcate the optimistic and pessimistic regimes. Instead the exchange rate fluctuates rapidly from the optimistic to the pessimistic equilibrium. This feature also shows up in the lower panel where we observe that optimistic and pessimistic weights alternate very quickly. Notice the difference with figure $2 \mathrm{~b}$. In this case waves of optimism and pessimism are long and protracted. Note that in both cases non-fundamental (bubble) regimes can occur.

How can these results be interpreted? How can waves of optimism and pessimism arise in an unpredictable ways, as shown in our model? The answer comes form the interaction between the two different beliefs, the existence of noise and the chartists who "feed on noise". The story then is the following. Noise generates an unpredictable sequence of exchange rate movements. The use of chartist (extrapolative) rules can transforms these into sustained movements in one direction. Typically this will be a direction towards one of the fundamental beliefs and away from the other. Thus, by pure accident, those who follow the former belief, say the optimistic one, will start making more profits than those who follow the latter, pessimistic, belief. As a result, the optimists will attract new followers, while the pessimists loose adherence. The optimistic belief becomes a focal point and a temporary new equilibrium, until a series of shocks that are strong enough and that get reinforced by the chartist forecasting rules lead to a movement towards the pessimistic equilibrium. It may not be clear to the reader now that these beliefs lead to equilibrium points (attractors) but this will become clear in the next section. When the divergence in the beliefs is weak relative to the stochastic shocks, the exchange rate 
Figure 1: Simulations in the time domain: optimism-pessimism level around the fundamental - benchmark case
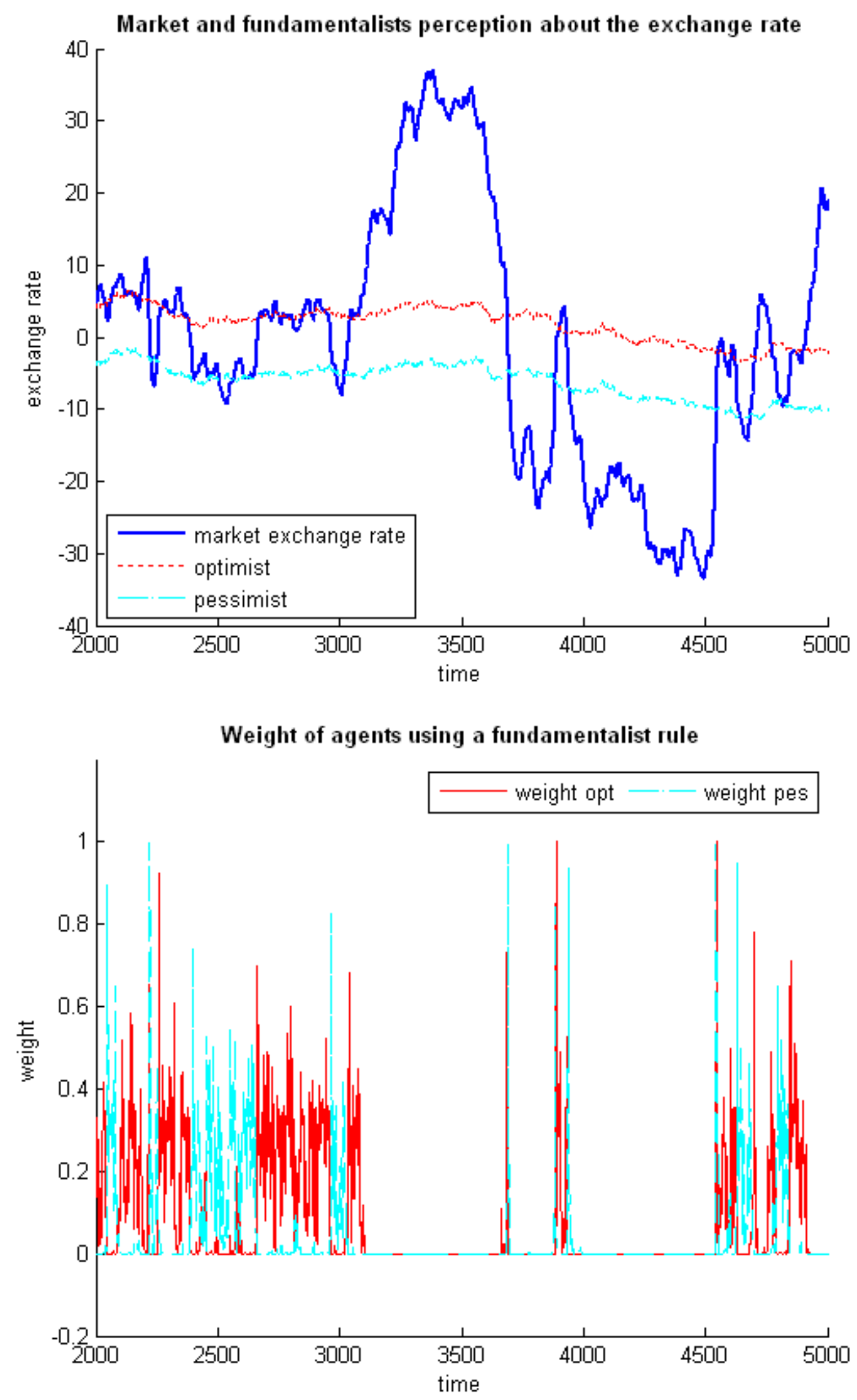
Figure 2: Simulations in the time domain: weak vs strong optimism-pessimism level around the fundamental
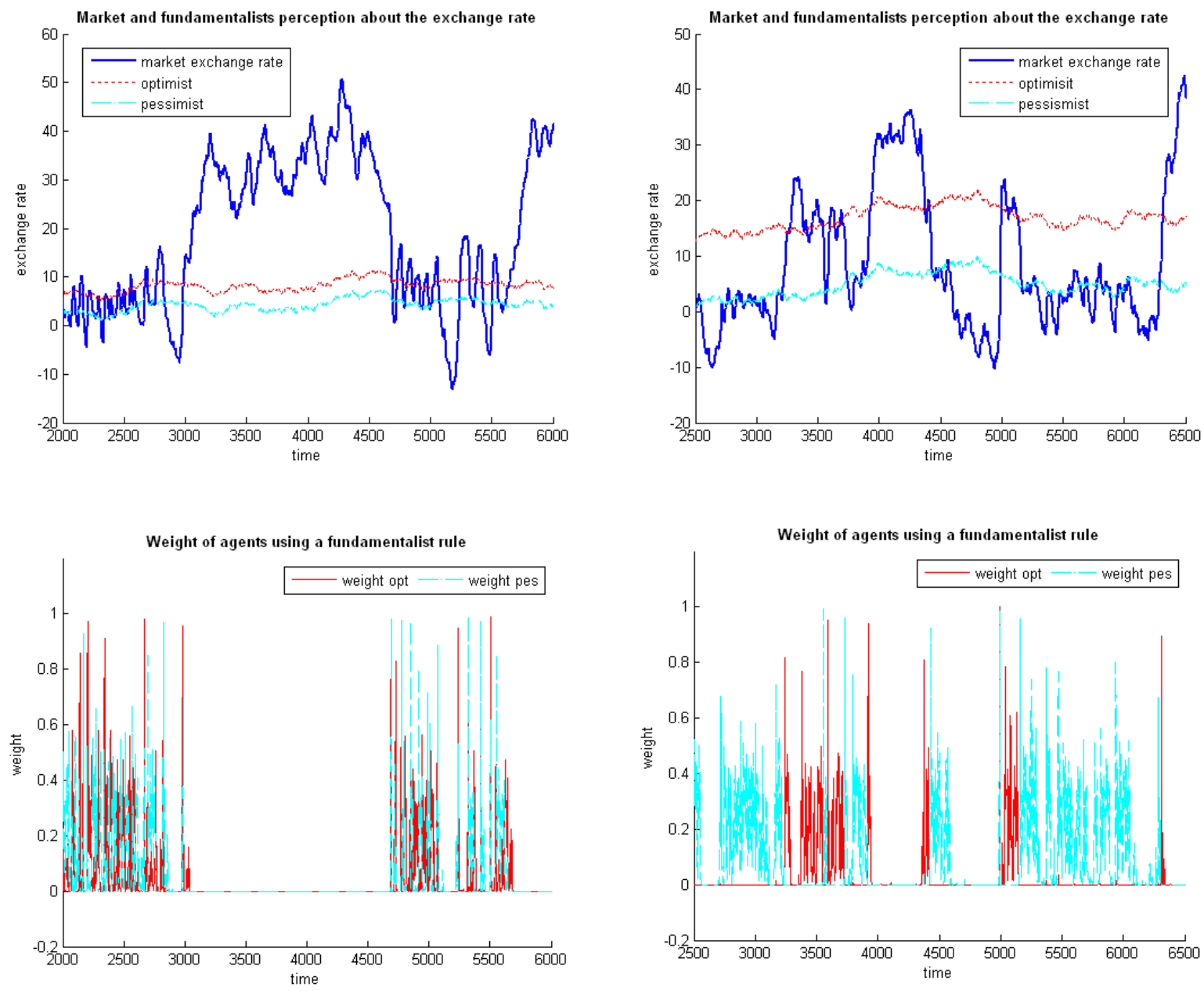

$2 \mathrm{a}$ (weak divergence)

$2 \mathrm{~b}$ (strong divergence) 
cannot settle for long in one of the two belief equilibria and it will fluctuate between these two equilibria with a high frequency. When the divergence in the beliefs is strong, the exchange rate can settle for a long time in the neighborhood of one of the belief equilibria without being attracted by the other. Why don't we stay then in one of these equilibria? The answer is that the chartist rules create the potential for bubble dynamics. This dynamics was also found in De Grauwe and Grimaldi (2006). When inevitably a bubble develops it will move the exchange rate away from the particular belief equilibrium in which it happens to be. The bubble can then either reach the other belief equilibrium or it will develop into a true bubble, disconnected from the fundamental and the beliefs agents have about this fundamental.

\section{Sensitivity analysis in a deterministic environment}

In this section we analyze the nature of the different equilibria and we perform a sensitivity analysis, i.e. we study how the equilibria are affected by the different parameters of the model. We do this by stripping the model of its stochastics, except for the initial shock to the exchange rate (the initial conditions). We set the true fundamental value $s_{t}^{*}=0$. As a result, the exchange rate can be interpreted as a deviation from its fundamental value.

We first show the result of simulating the model for different initial values and for different values of the degree of divergence in beliefs $(2 a)$. We show the results in figure 3. On the $\mathrm{x}$-axis we have the initial values of the exchange rate. These can be positive or negative because we can start the simulation with an exchange rate that is above or below the fundamental value. The y-axis shows the increasing levels of divergence in beliefs. On the vertical axis we plot the equilibrium value of the exchange rate. This is the fixed point to which the exchange rate converges after having been shocked initially. We can now interpret the results as follows. We start with low values of divergence (we are close to 0 on the $y$-axis). We then observe that for sufficiently small initial shocks, the exchange rate converges to zero (the fundamental value). When the initial shock is large enough the exchange rate will not converge to zero but to a positive, or negative number, and it will stay there. These are the non-fundamental attractors in the model. In a stochastic environment they lead to the occurrence of bubbles. This feature was also found in De Grauwe and Grimaldi (2006) and was explained there.

Let us now move along the y-axis. The degree of divergence increases. At some point 
we reach a bifurcation. We now obtain two fundamental equilibria. They correspond to the optimistic and the pessimistic belief equilibria identified in the previous section. Note the interesting feature that at the point of bifurcation the true fundamental $\left(s_{t}^{*}=0\right)$ ceases to act as an attractor and the beliefs take over this function. We also note that as we move along the y-axis the area of non-fundamental (bubble) equilibria shrinks. Finally we also observe that the boundary between the fundamental equilibria (whether real or beliefs) and the bubble equilibria is discontinuous.

Figure 3: Deterministic simulations: sensitivity to optimism-pessimism level and initial conditions

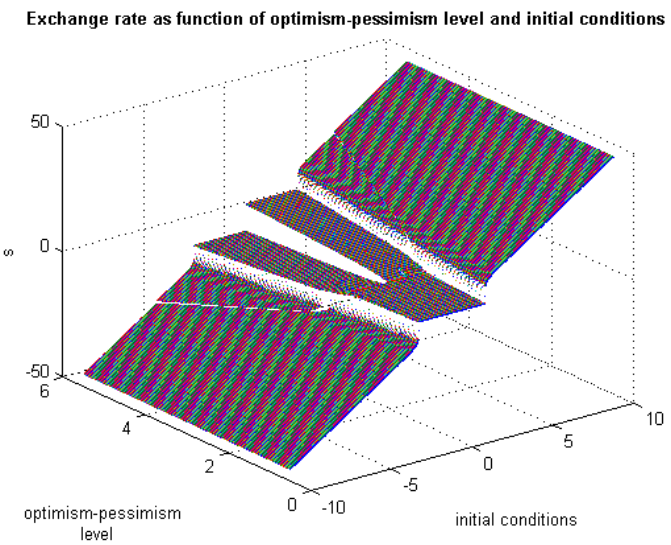

We now present additional results in which we allow other parameters of the model to change. In figures $4 \mathrm{a}$ and $4 \mathrm{~b}$ we show the results of simulations in which we allow the parameter $\beta$ (the extrapolation parameter of chartists) to vary.

Figure 4: Deterministic simulation: sensitivity to beta and initial conditions

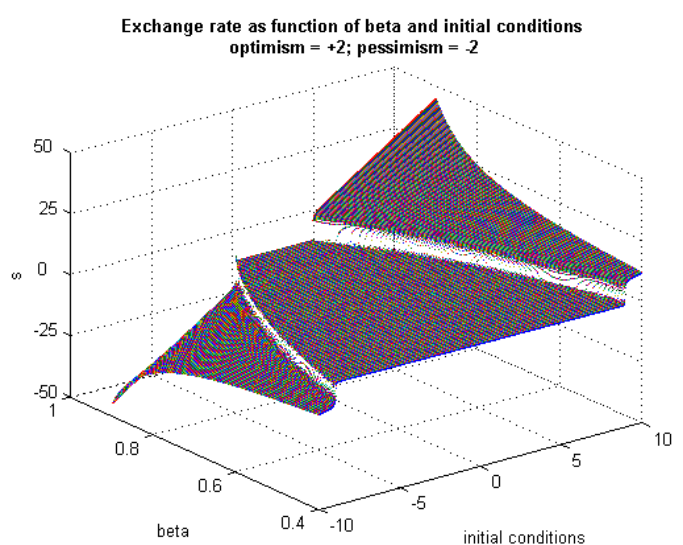

$4 \mathrm{a}$

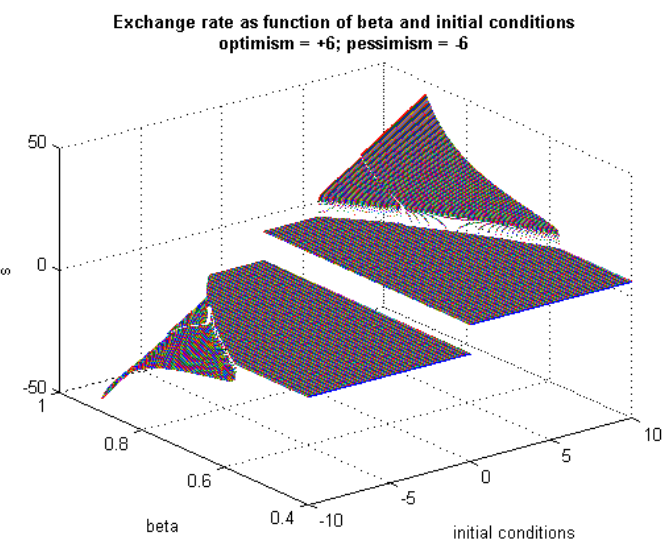

$4 \mathrm{~b}$ 
We also distinguish between two cases, a low divergence in beliefs case (left panel) and a high divergence in beliefs case. Take the case of low divergence first. We observe that as $\beta$ increases, the surface collecting the fundamental equilibria shrinks and the surface of non-fundamental equilibria increases. Thus, when the extrapolation parameter is high, small initial disturbances lead the exchange rate towards a non-fundamental equilibrium. Note that in this case of low divergence in beliefs, the true fundamental $\left(s^{*}=0\right)$ acts an attractor. This feature contrasts with the results obtained in the right hand panel. There we find two fundamental attractors, the optimistic belief attractor (which is positive) and the pessimistic belief attractor (which is negative). Depending on the initial shock the exchange rate will settle either in the optimistic or in the pessimistic attractors. As in the left hand panel we find that the surface of these fundamental attractors shrinks with an increasing $\beta$.

A final sensitivity analysis is presented in figures $5 \mathrm{a}$ and $5 \mathrm{~b}$. We now allow the parameter $\gamma$ to change. This is the "intensity of choice" parameter that regulates the switching behavior. A high $\gamma$ implies that changes in relative profitability of forecasting rules have a strong influence on agents' willingness to switch from one rule to another. We show as before the cases of low and high divergences in beliefs. We find that as agents become more willing to switch (high $\gamma$ ) the surface of fundamental equilibria shrinks and the surface of bubble equilibria expands. Note that when $\gamma=0$ we obtain only fundamental equilibria. This is a situation in which agents keep the same forecasting rule whatever its profitability. We also observe that in the high divergence case a small positive value of $\gamma$ is sufficient to generate two fundamental equilibria (an optimistic and a pessimistic belief equilibrium). When the divergence is small we need large values of $\gamma$ to reach a bifurcation point.

We observe form figure 5a that there are regions where the border between different types of equilibrium is complex. We illustrate this in figure 6 by "taking a slice" at a value of gamma $=3.5$. We then obtain a two dimensional picture showing the attractors for different initial conditions and for the same gamma $=3.5$.

We now observe that small differences in the initial conditions can lead the exchange rate to be attracted by a very different equilibrium point. This feature is made even clearer by blowing up figure 6 . We then obtain figure 7 . We observe that a very small displacement in the initial condition can lead the attractor to jump from a positive to 
Figure 5: Deterministic simulations: sensitivity to gamma and initial conditions

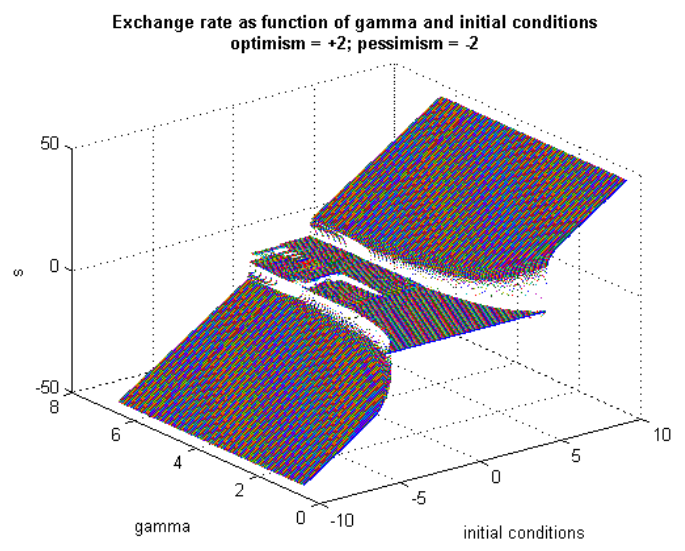

$5 \mathrm{a}$

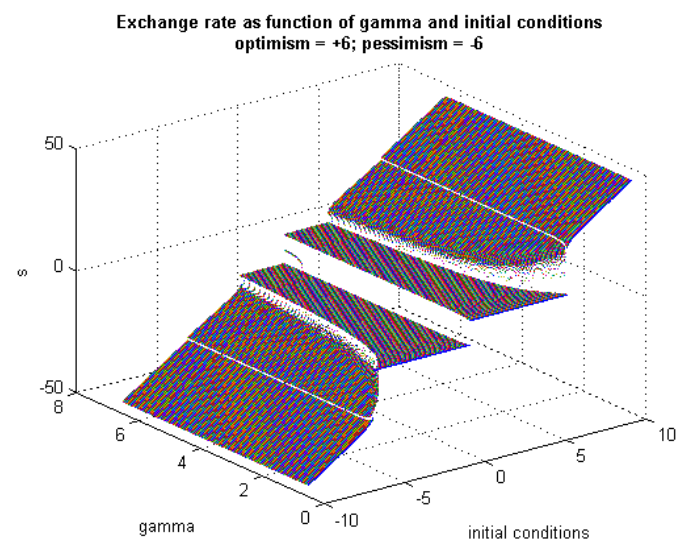

$5 \mathrm{~b}$

Figure 6: Deterministic simulations: sensitivity to initial conditions

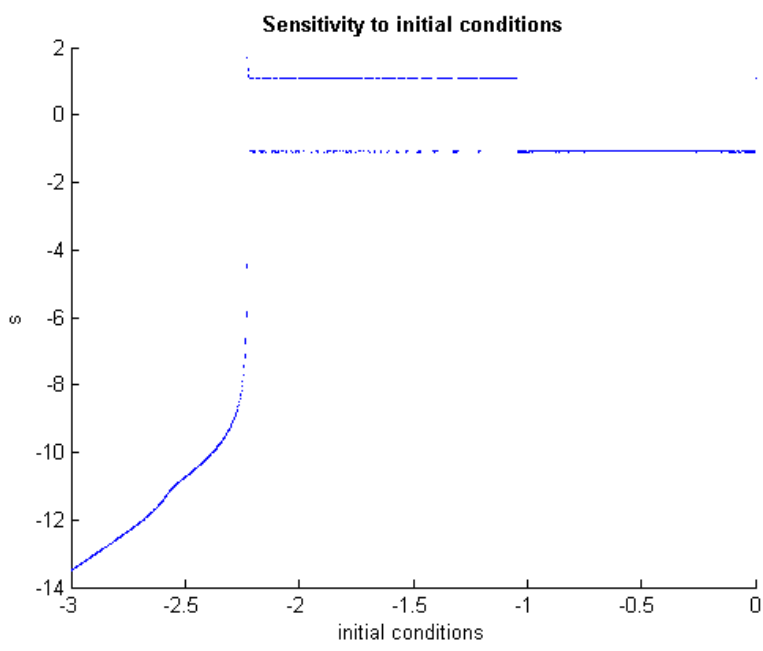


Figure 7: Deterministic simulations: sensitivity to initial conditions

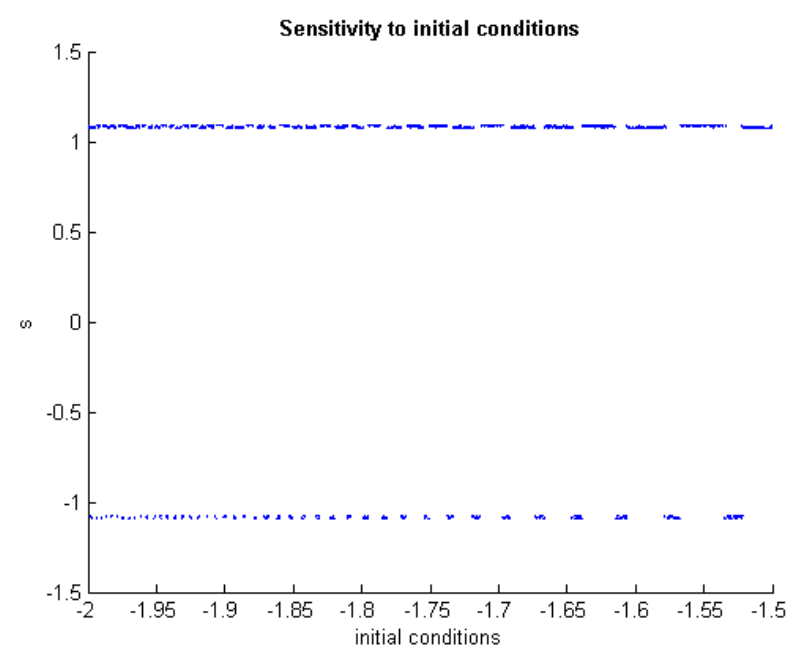

a negative number and vice versa. This feature suggests that the boundary between the two equilibria is fractal in nature. This feature has an important implication, i.e. in a stochastic environment it leads to sensitivity of the future time path of the exchange rate to initial conditions. We analyze this further in the next section.

\section{Sensitivity to initial conditions in a stochastic en- vironment}

The nonlinearities and the discontinuities in the model create a potential for "sensitivity to initial conditions". We analyze this feature as follows. We simulate the model in the time domain assuming two different initial conditions for the exchange rate. The difference in the initial conditions is set at 0.1 . The rest of the stochastics is identical in the two simulations. Thus, the stochastic realizations of the fundamental variable and the noise terms in the exchange rate equation are identical. We show two examples of such simulations in figures $8 \mathrm{a}(a=2)$ and $8 \mathrm{~b}(a=6)$.

We observe that a small difference in the initial conditions can create periods during which the two exchange rates exhibit a completely different time pattern, with different waves of optimism and pessimism, and different occurrences of bubbles. Thus it appears that small differences in the initial conditions can create a different "history" of the exchange rate. This different historical pattern is not the result of differences in the underlying fundamental variable. It results from the fact that the small difference in the 


\section{Figure 8: Sensitivity to initial conditions in the time domain}

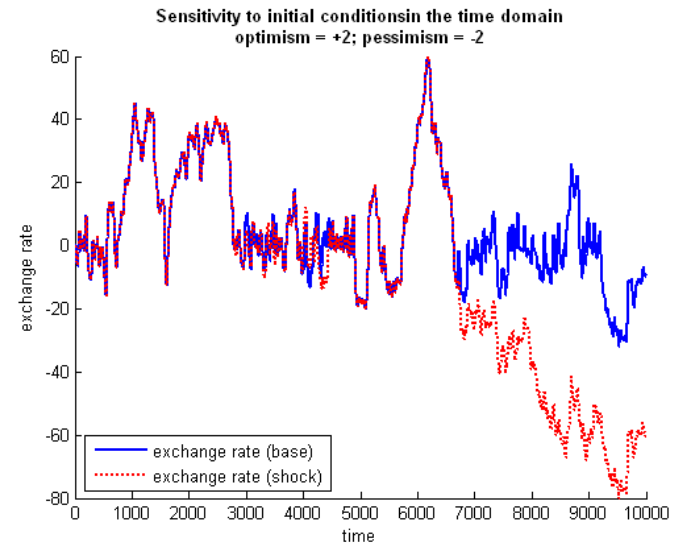

$8 \mathrm{a}$

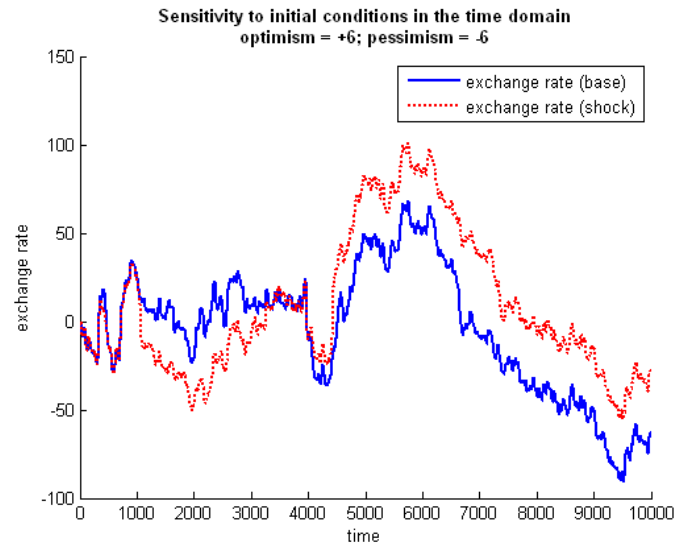

$8 \mathrm{~b}$

initial conditions is sufficient to move the exchange rate to a different fundamental belief equilibrium. This then leads to different waves of optimism and pessimism and possibly to different bubbles. For the outside observer it appears that the exchange rate is driven by different fundamental variable. It will not be surprising that in the world we describe here the outside observer will be tempted to develop quite different stories about the underlying fundamental.

The "sensitivity to initial conditions" does not appear as a feature in all simulations. We found that in many simulations the two exchange rates converge to exactly the same time path. In order to find out the frequency of the occurrence of sensitivity to initial conditions, we repeated the simulations many times. In addition, we checked the importance of some parameter values in generating sensitivity to initial conditions. We show the results in figures $9 \mathrm{a}$ and $9 \mathrm{~b}$. The horizontal axis shows increasing values of $\gamma$ (the switching parameter). For each value of $\gamma$ we performed 100 simulations of 10,000 periods each and counted the number of times sensitivity to initial conditions occurred. Each point shows the percentage of time this was the case. The left hand side panel shows the results for the intermediate level of divergence in beliefs $(a=2)$ and the right hand side panel for a high level of divergence $(a=6)$. We observe that the occurrence of sensitivity to initial conditions increases with $\gamma$. Thus the more agents are willing to switch to another rule in response to changes in relative profitability the more often sensitivity to initial conditions will be observed. The different divergence of opinions does not alter this result ${ }^{11}$.

\footnotetext{
${ }^{11}$ We tested for other levels of divergence. The results were not affected.
} 
Figure 9: Percentage of times exchange rate series show different paths due to a different initial shock conditional on gamma

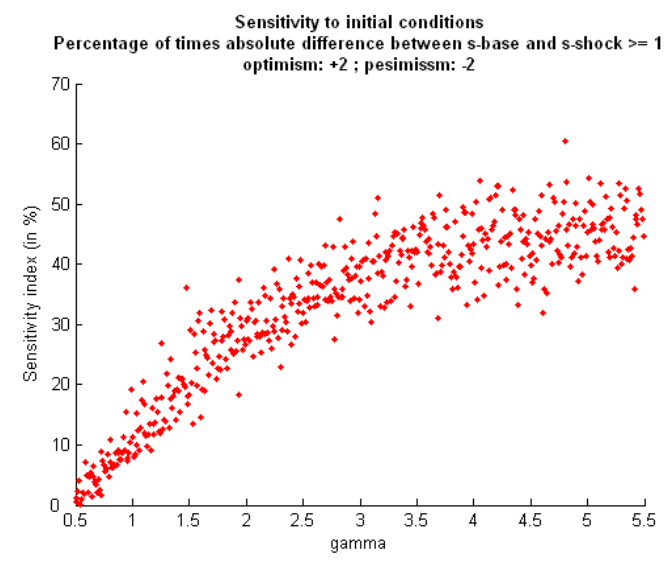

$9 \mathrm{a}$

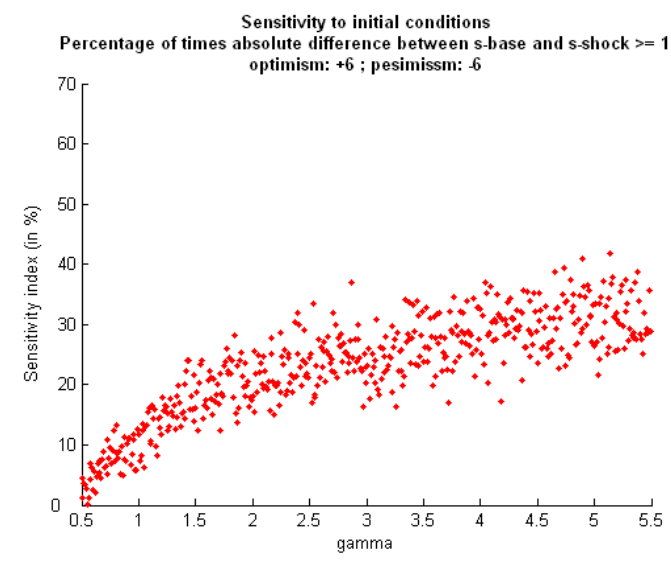

$9 \mathrm{~b}$

\section{Sensitivity to changes in beliefs}

The model also produces a strong sensitivity to changes in the beliefs about the underlying fundamental. We show this feature by simulating the model assuming a small change in a keeping the parameter gamma constant at the value of 5 . In the base simulation we set $a=2$. We compare the results with a simulation where we have set set $a=2.1$. The stochastics is identical in the two simulations, i.e. the initial conditions and the stochastic realizations of the fundamental are the same. An example of such a simulation is shown in figure 10. We observe that a slight change in the beliefs about the underlying fundamental can have the effect of changing the future history of the exchange rate in a substantial way, with different waves of optimism and pessimism.

Figure 11 shows the results when the change in beliefs is assumed to be stronger (but still relatively modest). We now set $a=2$ in the base simulation and $a=3$ in the shock simulation. The divergences in the time path of the exchange rates are spectacular. It now appears to the outsider that the two exchange rates are often driven by very different fundamentals. This, however, is not the case. What drives these divergences is a relatively small difference in the beliefs of the agents about the underlying fundamental.

We tested the frequency of these divergences (as in figures 9a and 9b) by computing the number of times the two exchange rate series deviated from each other. As in figure 9 we did that for different values of $\gamma$. For each value of $\gamma$ we performed 100 simulations of 10,000 periods each and computed the percentage of times the exchange rate devia- 
Figure 10: Sensitivity to the fundamental belief in the time domain

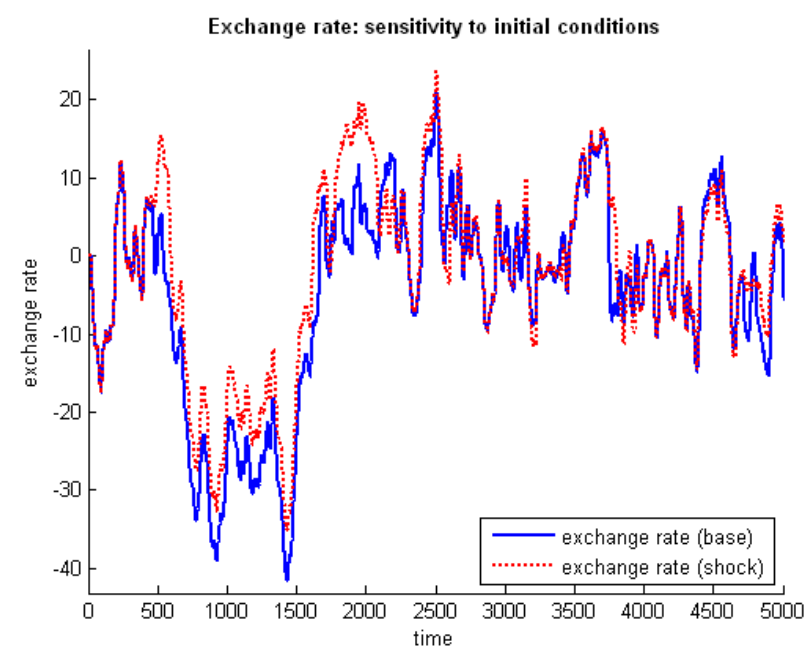

Figure 11: Sensitivity to the fundamental belief in the time domain

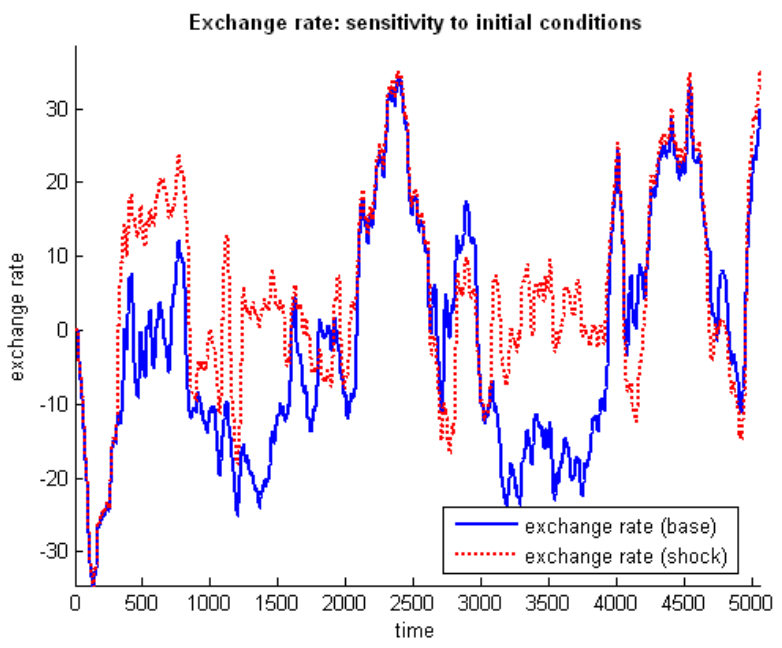


tions exceeded 1 . The results are shown in figures $12 \mathrm{a}$ and $12 \mathrm{~b}$. We now find that these divergences are observed most of the time. Thus relatively small changes in beliefs have profound effects on the time path of the exchange rate even when the underlying fundamental is not affected. Put differently, changes in beliefs have powerful effects independent from changes in the "underlying reality" that drives the exchange rate.

Figure 12: Percentage of times different levels of optimism-pessimism generate different paths of the exchange rate conditional on gamma

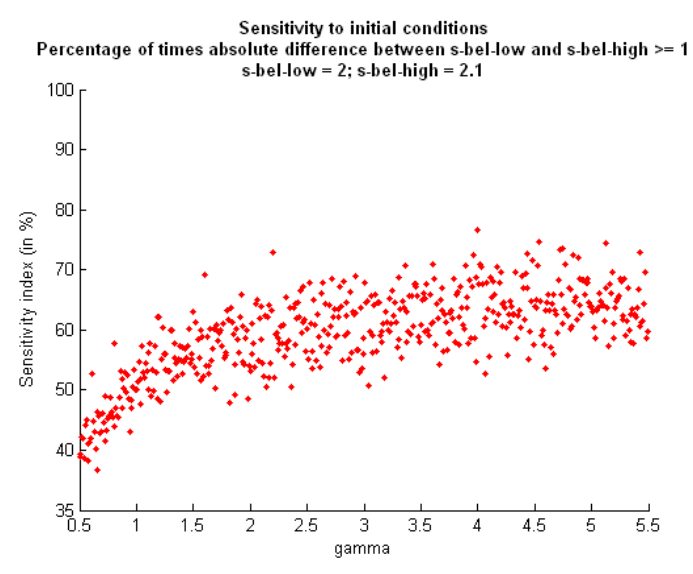

$12 \mathrm{a}$

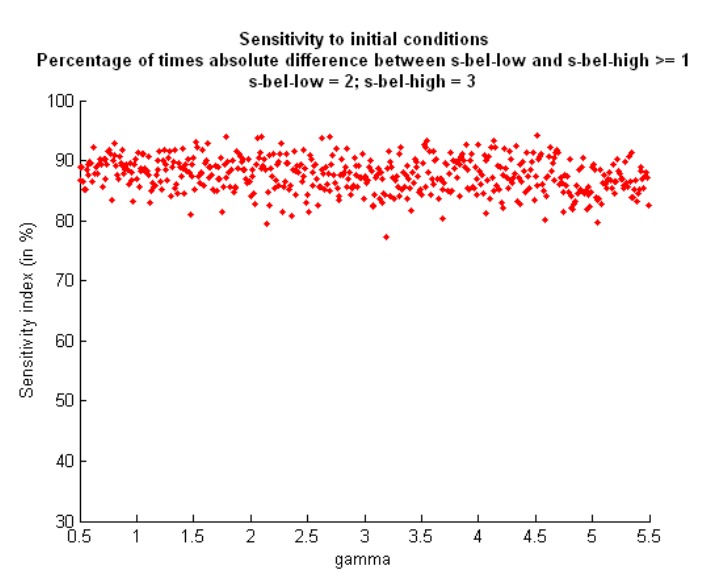

$12 \mathrm{~b}$

\section{Empirical testing}

In this section we analyze if our exchange rate model is capable of replicating the stylized facts typically observed in foreign exchange market data. Our main focus will be on the distribution of the exchange rate returns (fatness of the tails), unit root properties of the exchange rate and ARCH effects.

\subsection{Fat tails}

There is a large empirical literature documenting the existence of fat tails and excess kurtosis in the foreign exchange markets. (For a survey see De Grauwe and Grimaldi (2006)). We analyze whether our model is capable of replicating this finding. In order to do so, we simulated our model for different values of the divergence of beliefs parameters and computed the kurtosis and the Hill index (which is often used as a measure of fat tails $)^{12}$. We repeated each simulation 100 times and report the median kurtosis and the

\footnotetext{
${ }^{12}$ In De Grauwe and Grimaldi(2006) we performed a similar analysis allowing other parameters of the model to change.
} 
median Hill index. We show the results in table 1.

The first column shows the different values of the parameter $a$ measuring the divergence of beliefs. We let this parameter increase from 0 (no divergence) to 12. The second column shows the median kurtosis. The median is obtained from 100 simulations each of 10,000 periods. We observe that for all values of the divergence of belief parameter we obtain excess kurtosis, i.e. the concentration of the returns around the mean is too high to be represented by a normal distribution (the kurtosis of a normal distribution is 3 ). The same phenomenon has been observed in the real data. We observe a hump shaped behavior of the kurtosis, i.e. it increases first with the value of the divergence parameter and then tends to decline for large values.

The last three columns show the Hill index using different cutoff points of the tail. This index measures the fatness degree of the tails of the distribution of the exchange rate returns. The values obtained correspond to those obtained in the empirical literature (see Koedijk, et al. (1992)). We observe a similar hump shaped pattern, i.e. when the divergence of beliefs starts increasing the Hill indices decline first, but then increase after some sufficiently large value of divergence. We have found the same results for a large set of values of the parameters of the model. In appendix we show some representative histograms of the returns obtained under different assumptions of divergence of beliefs.

These results lead to the following interpretation. First our model is capable of replicating a widely observed phenomenon, i.e. that exchange rate returns exhibit excess kurtosis and fat tails. Second, the emergence of divergence in beliefs tends to make the tails of the distribution of the returns fatter, and leads to more density around the mean . This effect is the strongest when divergence is not too high. The interpretation of these results is the following. When the exchange rate moves around one particular type of equilibrium, volatility is low. The existence of divergence of beliefs, however, leads to regular switches from one type of equilibrium to another. These switches coincide with greater turbulence and extreme changes in the exchange rate. When the divergence of beliefs is very high, these switches become less frequent (as was illustrated in section 3).

A more intuitive way to interpret these results is as follows. Volatility is low when there is a consensus of beliefs about the fundamental. Exchange rate changes are then relatively low. At some point, due to stochastic shocks, this consensus unravels. As a consequence, the market starts searching for a new consensus about the fundamental exchange rate. 
That is the time when turbulence sets in and volatility increases. Until a new consensus emerges.

Table 1: Empirical findings: probability distribution of returns

\begin{tabular}{ccccc} 
& & \multicolumn{3}{c}{ Median Hill index } \\
\cline { 3 - 5 } Divergence Beliefs & Med Kurtosis & $2.5 \%$ tail & $5 \%$ tail & $10 \%$ tail \\
\hline 0 & 4.32 & 5.73 & 5.16 & 4.31 \\
2 & 6.00 & 3.93 & 3.98 & 3.74 \\
4 & 9.39 & 3.25 & 3.60 & 3.48 \\
6 & 9.61 & 3.83 & 4.02 & 3.68 \\
8 & 4.79 & 4.58 & 4.32 & 3.95 \\
10 & 4.68 & 4.91 & 4.75 & 4.11 \\
12 & 4.85 & 4.96 & 4.73 & 4.11 \\
\hline
\end{tabular}

Median values are computed out of 100 samples of 10000 observations each Parameter values: gamma $=3$, initial shock $=-2$, beta $=0.9$

\subsection{Unit root of exchange rate level}

The empirical evidence about exchange rates overwhelmingly shows that exchange rates follow a unit root process. We now turn to the question of whether the exchange rate series generated by our model can be described by a unit root process. Formally, when defining the exchange rate level as $s_{t}=\alpha s_{t-1}+\varepsilon_{t}$, where $\varepsilon_{t}$ is a stationary process, one is normally not able to reject the hypothesis of $\alpha$ being equal to 1 . To test this hypothesis we simulate the model for a given level of divergence of beliefs over 10000 thousand periods and perform the Dicky-Fuller unit root test. To make sure that our results are not driven by a particular stochastic simulation we repeat the experiment 100 times and then we compute the number of times the test rejects the null hypothesis of $a=1$. The results are reported in table 2 .

Table 2: Empirical findings: unit root test

\begin{tabular}{|c|c|c|c|}
\hline \multirow[b]{2}{*}{ Divergence Beliefs } & \multicolumn{2}{|c|}{ Range AR coefficient } & \multirow{2}{*}{$\begin{array}{c}\text { UR test ( } n^{\circ} \text { rejections) } \\
\text { alpha }=5 \%\end{array}$} \\
\hline & Low & High & \\
\hline 0 & 0.99989 & 1.00077 & 0 \\
\hline 2 & 0.99981 & 1.00048 & 0 \\
\hline 4 & 0.99982 & 1.00039 & 0 \\
\hline 6 & 0.99990 & 1.00063 & 0 \\
\hline 8 & 0.99987 & 1.00048 & 0 \\
\hline 10 & 0.99988 & 1.00042 & 0 \\
\hline 12 & 0.99994 & 1.00040 & 0 \\
\hline
\end{tabular}

Values computed out of 100 samples of 10000 observations each

Parameter values: gamma $=3$, initial shock $=-2$, beta $=0.9$

Our results do not reject the null hypothesis of a unit root in the exchange rate level. 
In table 2 we also report the lowest and the highest value of the estimated autoregressive coefficient of the exchange rate model specified above throughout the 100 repetitions. Judging by the low level of divergence in the estimated parameter range one can be confident about the accuracy of this finding. Also interesting is that the unit root property of the spot exchange rate level generated by the model does not depend upon the degree of divergence of beliefs.

\subsection{ARCH effects}

Finally we analyze whether in our model periods of high and low exchange rate volatility tend to cluster. This clustering of volatility has been widely observed in foreign exchange markets (see De Grauwe and Grimaldi (2006)). The typical statistical framework used to study this non-linear dependency of financial market data is the Autoregressive Conditional Heteroskedastic $(\mathrm{ARCH})$ model. We define the following an $\mathrm{ARCH}(1,1)$ model:

$$
\begin{aligned}
\Delta s_{t} & =c+\varepsilon_{t} \\
\sigma_{\varepsilon, t}^{2} & =d+\rho \sigma_{\varepsilon, t-1}^{2}+\epsilon_{t}
\end{aligned}
$$

where $\epsilon_{t}$ is an normally distributed $I I D$ process with $E\left[\epsilon_{t}\right]=0$ and $E\left[\epsilon_{t}^{2}\right]=\sigma_{\epsilon}^{2}$.

As in the two previous exercises, we simulate the model 100 times over 10000 periods for a given value of divergence of beliefs. Each time we perform both the ARCH test and Ljung-Box test. On table 3 we report the number of times that the null-hypothesis of no $\mathrm{ARCH}$ effects is rejected.

Table 3: Empirical findings: ARCH effects

\begin{tabular}{ccc} 
Divergence Beliefs & $\begin{array}{c}\text { GARCH test }\left(n^{\circ} \text { of rejections) }\right. \\
\text { alpha }=5 \%\end{array}$ & $\begin{array}{c}\text { LB-test }\left(n^{\circ} \text { of rejections) }\right. \\
\text { alpha }=5 \%\end{array}$ \\
\hline 0 & 100 & 100 \\
2 & 100 & 100 \\
4 & 100 & 100 \\
6 & 100 & 100 \\
8 & 100 & 100 \\
10 & 100 & 100 \\
12 & 100 & 100 \\
\hline
\end{tabular}

Values computed out of 100 samples of 10000 observations each Parameter values: gamma $=3$, initial shock $=-2$, beta $=0.9$

Overall both tests reject the null of no ARCH effects independently of the degree of divergence of beliefs. 
Throughout the analysis of the three stylized facts that we have studied in this section we have been particularly careful in also considering the case of no divergence in beliefs. In doing so, we show that our results are not driven by the inclusion of a belief bias with respect to the fundamental. In other words, we are able to replicate all the empirical stylized facts present in the foreign exchange market data both in the presence and in the absence of divergence of beliefs. Furthermore, in the analysis of the distributions of the returns around its mean we analyze the relevance of increasing the degree of divergence in beliefs.

\section{Conclusion}

Uncertainty about how the economy functions leads to divergences in beliefs. This was very well illustrated in recent years when two sets of beliefs emerged about the fundamental value of the dollar. According to one school of thought, represented by among others, Obstfeld and Rogoff, the unsustainable current account deficits of the US would lead to a major decline of the dollar. For these believers the fundamental value of the dollar was way below the market value. Another school of thought (represented by Hausmann and Sturzenegger) had it that there is no problem with US current account deficits and foreign debt because in fact if correctly measured, there is no net foreign debt. Fore these believers the fundamental value of the dollar was high enough so that no adjustment in the market rate was called for.

In this paper we have modeled how the existence of different beliefs about the underlying fundamental value of the currency affects the dynamics of the exchange rate. We found that a divergence of beliefs creates the potential for waves of optimism and pessimism that alternate in an unpredictable way. These waves are disconnected from the underlying (objective) fundamental value. We also found that in such a world there is "sensitivity to initial conditions", i.e. small changes in beliefs can fundamentally alter the time path of the exchange rate. Finally, divergence of beliefs creates regime switches when one belief consensus about the fundamental unravels and the market searches for a new consensus. During these periods of regime switching, turbulences sets in and large changes in the exchange rates occur. 
Appendix: Histograms of returns under different beliefs

Figure 13: Empirical findings: probability distribution of returns
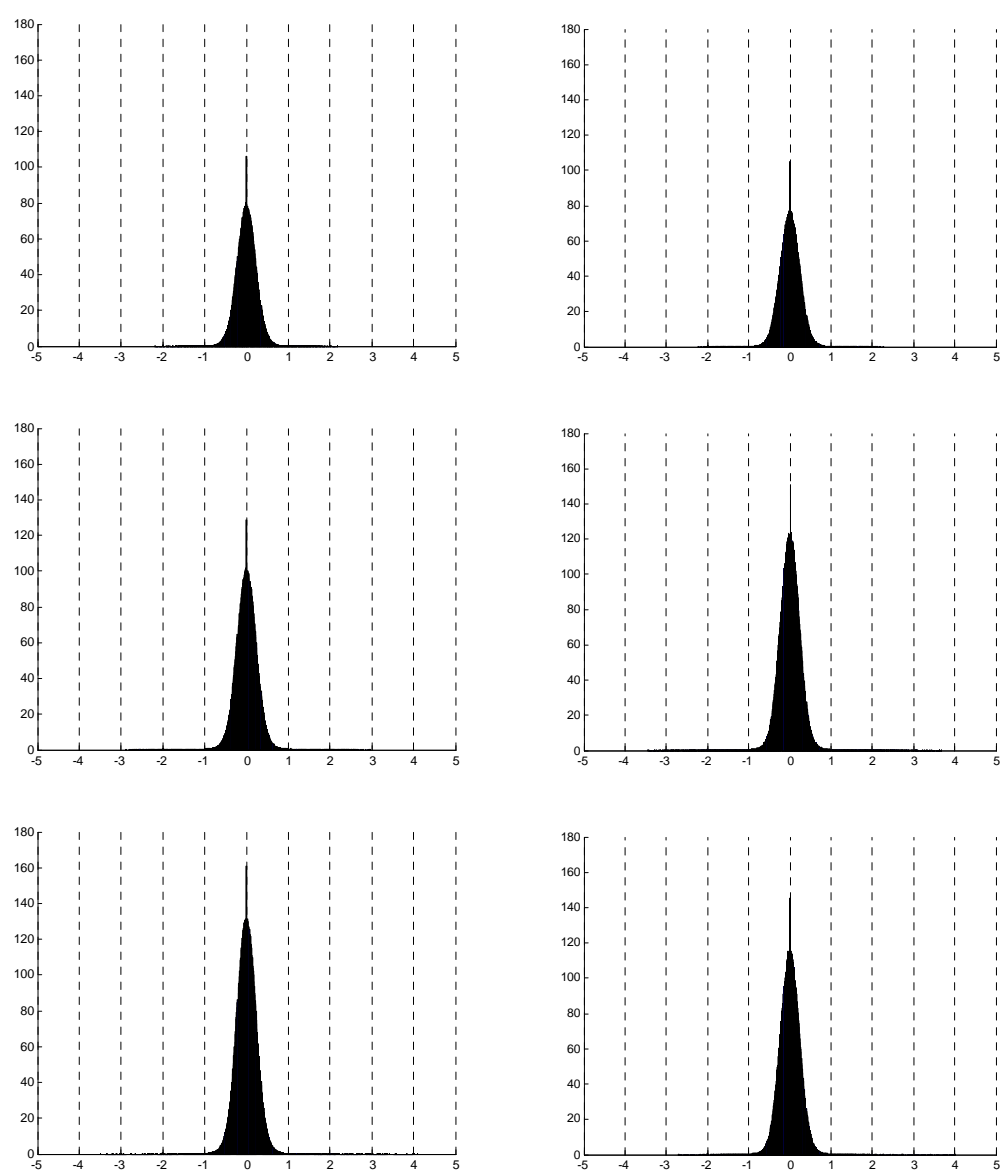


\section{References}

[1] Anderson, S., de Palma, A. and Thisse J.-F. (1992). Discrete Choice Theory of Product Differentiation. Cambridge, MA: MIT Press.

[2] Blanchard, O.J. and Fischer, S. (1989). Lectures in Macroeconomics. Cambridge, MA: MIT Press.

[3] Brock, W. and Hommes, C. (1995). A Rational Route to Randomness. Econometrica, 65: 1059-1095.

[4] Brock, W. and Hommes, C. (1998). Heterogeneous Beliefs and Routes to Chaos in a Simple Asset Pricing Model. Journal of Economic Dynamics and Control, 22:12351274.

[5] Brunnermeier, M. (2001). Asset Pricing under Asymmetric Information: Bubbles, Crashes, Technical Analysis, and Herding. Oxford University Press.

[6] Corrado, L., Miller, M. and Zhang, L. (2007). Bulls, Bears and Excess Volatility: can currency intervention help? International Journal of Finance and Economics, 12(3)

[7] De Grauwe, P. and Grimaldi, M. (2005). Heterogeneity of agents, transaction costs and the exchange rate. Journal of Economic Dynamics and Control, 29: 691-719.

[8] — (2006). The Exchange Rate in a Behavioral Finance Framework. Princeton, NJ: Princeton University Press.

[9] Evans, M., and Lyons, R. (2002), Order Flow and Exchange Rate Dynamics, Journal of Political Economy, 110(1), 170-180.

[10] Frankel, J., and Froot, K. (1990). Chartists, Fundamentalists and Trading in the Foreign Exchange Market. American Economic Review, 80:181-185.

[11] Hausmann, R. and Sturzenegger, F. (2006). Why the US Current Account Deficit is Sustainable. International Finance, 9(2): 223-240.

[12] Hommes, C. (2006), Heterogenous Agents Models in Economics and Finance, in Tesfatsion and Judd, (eds.), Handbook of computational Economics, vol. 2, Elsevier. 
[13] Kahneman, D., Knetsch, J. and Thaler, R. (1991). The Endowment Effect, Loss Aversion and Status Quo Bias. Journal of Economic Perspectives, 5: 193-206.

[14] Kahneman, D. and Thaler, R. H. (2006). Utility Maximization and Experienced Utility, Journal of Economic Perspectives, 20(1): 221-234.

[15] Keynes, John M. (1936). The General Theory of Employment, Interest and Money, Macmillan \& Co.

[16] Kindelberger, Charles P. (1978). Manias, Panics, and Crashes: A History of Financial Crises, John Wiley \& Sons, Inc.

[17] Kirman, A. and Teyssière, G. (2002). Microeconomic Models for Long Memory in the Volatility of Financial Time Series. Studies in Nonlinear Dynamics and Econometrics, 5: $137-156$

[18] Koedijk, K., Stork, P., and de Vries, C., (1992), Foreign exchange regime differences viewed from the tails, Journal of International Money and Finance, 11:462-473.

[19] Lux, T. (1998). The Socio-Economic Dynamics of Speculative Markets: Interacting Agents, Chaos, and Fat Tails of Return Distributions. Journal of Economic Behavior Ef Organization, 33: 143-165.

[20] Lux, T. and Marchesi, M. (1999). Scaling and Criticality in a Stochastic Multi_Agent Model of a Financial Market, Letters to Nature, 397: 498 - 500

[21] Lux, T. and Schornstein, S. (2005). Genetic Learning as an Explanation of Stylized Facts of Foreign Exchange Markets. Journal of Mathematical Economics 41:169-196.

[22] Obstfeld, M. (2005). America's Deficit, the World's Problem. Monetary and Economic Studies 23: No.S-1

[23] Obstfeld, M. and Rogoff, K. (2005). The Unsustainable US Current Account Position Revisited. NBER Working Paper 10869

[24] Sargent, T. (1993). Bounded Rationality in Macroeconomics. Oxford University Press.

[25] Shiller, R. (2000). Irrational Exuberance. Princeton University Press. 
[26] Shleifer, A. (2000). Introduction to Behavioral Finance. Oxford: Clarendon.

[27] Simon, H. (1957). Models of Man. NewYork: JohnWiley.

[28] Taylor, M. and Allen, H. (1992). The use of technical analysis in the foreign exchange market. Journal of International Money and Finance 11: 304-314.

[29] Thaler, R. (1994). Quasi Rational Economics. NewYork: Russell Sage Foundation.

[30] Tversky, A. and Kahneman, D. (1981). The framing of decisions and the psychology of choice. Science 211: 453-458. 


\title{
CESifo Working Paper Series
}

\author{
(for full list see www.cesifo-group.de)
}

1900 Tomer Blumkin and Efraim Sadka, On the Desirability of Taxing Charitable Contributions, January 2007

1901 Frederick van der Ploeg and Reinhilde Veugelers, Higher Education Reform and the Renewed Lisbon Strategy: Role of Member States and the European Commission, January 2007

1902 John Lewis, Hitting and Hoping? Meeting the Exchange Rate and Inflation Criteria during a Period of Nominal Convergence, January 2007

1903 Torben M. Andersen, The Scandinavian Model - Prospects and Challenges, January 2007

1904 Stephane Dees, Sean Holly, M. Hashem Pesaran and L. Vanessa Smith, Long Run Macroeconomic Relations in the Global Economy, January 2007

1905 Richard Jong-A-Pin and Jakob De Haan, Political Regime Change, Economic Reform and Growth Accelerations, January 2007

1906 Sascha O. Becker and Peter H. Egger, Endogenous Product versus Process Innovation and a Firm's Propensity to Export, February 2007

1907 Theo S. Eicher, Chris Papageorgiou and Oliver Roehn, Unraveling the Fortunates of the Fortunate: An Iterative Bayesian Model Averaging (IBMA) Approach, February 2007

1908 Liliana E. Pezzin, Robert A. Pollak and Barbara S. Schone, Efficiency in Family Bargaining: Living Arrangements and Caregiving Decisions of Adult Children and Disabled Elderly Parents, February 2007

1909 Christian Keuschnigg and Soren Bo Nielsen, Self-Selection and Advice in Venture Capital Finance, February 2007

1910 Rune Jansen Hagen and Gaute Torsvik, Irreversible Investments, Dynamic Inconsistency and Policy Convergence, February 2007

1911 Eric A. Hanushek and Ludger Woessmann, The Role of School Improvement in Economic Development, February 2007

1912 Bernard M. S. van Praag, Perspectives from the Happiness Literature and the Role of New Instruments for Policy Analysis, February 2007

1913 Volker Grossmann and Thomas M. Steger, Growth, Development, and Technological Change, February 2007 
1914 Margarita Katsimi and Thomas Moutos, Human Capital and the Feldstein-Horioka Puzzle, February 2007

1915 Oliver Roehn, Theo S. Eicher and Thomas Strobel, The Ifo Industry Growth Accounting Database, February 2007

1916 Ian Babetskii, Aggregate Wage Flexibility in Selected New EU Member States, February 2007

1917 Burkhard Heer, Alfred Maussner and Paul D. McNelis, The Money-Age Distribution: Empirical Facts and Limited Monetary Models, February 2007

1918 Yin-Wong Cheung, Menzie D. Chinn and Eijii Fujii, The Overvaluation of Renminbi Undervaluation, February 2007

1919 Jim Malley, Apostolis Philippopoulos and Ulrich Woitek, To React or Not? Fiscal Policy, Volatility and Welfare in the EU-3, February 2007

1920 Mattias Polborn, Competing for Recognition through Public Good Provision, February 2007

1921 Lars P. Feld and Benno Torgler, Tax Morale after the Reunification of Germany: Results from a Quasi-Natural Experiment, February 2007

1922 Robert S. Chirinko and Huntley Schaller, Fundamentals, Misvaluation, and Investment: The Real Story, February 2007

1923 Benno Torgler and Friedrich Schneider, Shadow Economy, Tax Morale, Governance and Institutional Quality: A Panel Analysis, February 2007

1924 Adrian Pagan and M. Hashem Pesaran, On Econometric Analysis of Structural Systems with Permanent and Transitory Shocks and Exogenous Variables, February 2007

1925 Hans-Werner Sinn, The Welfare State and the Forces of Globalization, February 2007

1926 Michael Smart, Raising Taxes through Equalization, February 2007

1927 Øystein Foros, Kåre P. Hagen and Hans Jarle Kind, Price-Dependent Profit Sharing as an Escape from the Bertrand Paradox, February 2007

1928 Balázs Égert, Kirsten Lommatzsch and Amina Lahrèche-Révil, Real Exchange Rates in Small Open OECD and Transition Economies: Comparing Apples with Oranges?, February 2007

1929 Aleksander Berentsen and Cyril Monnet, Monetary Policy in a Channel System, February 2007

1930 Wolfgang Ochel, The Free Movement of Inactive Citizens in the EU - A Challenge for the European Welfare State?, February 2007 
1931 James K. Hammitt and Nicolas Treich, Statistical vs. Identified Lives in Benefit-Cost Analysis, February 2007

1932 Wilhelm Kohler, The Bazaar Effect, Unbundling of Comparative Advantage, and Migration, February 2007

1933 Karsten Staehr, Fiscal Policies and Business Cycles in an Enlarged Euro Area, February 2007

1934 Michele Bernasconi and Paola Profeta, Redistribution or Education? The Political Economy of the Social Race, March 2007

1935 Axel Dreher, Martin Gassebner and Lars-H. R. Siemers, Does Terror Threaten Human Rights? Evidence from Panel Data, March 2007

1936 Naércio Aquino Menezes Filho and Marc-Andreas Muendler, Labor Reallocation in Response to Trade Reform, March 2007

1937 Gebhard Flaig and Timo Wollmershaeuser, Does the Euro-zone Diverge? A Stress Indicator for Analyzing Trends and Cycles in Real GDP and Inflation, March 2007

1938 Michael Funke and Michael Paetz, Environmental Policy Under Model Uncertainty: A Robust Optimal Control Approach, March 2007

1939 Byeongchan Seong, Sung K. Ahn and Peter A. Zadrozny, Cointegration Analysis with Mixed-Frequency Data, March 2007

1940 Monika Bütler and Michel André Maréchal, Framing Effects in Political Decision Making: Evidence from a Natural Voting Experiment, March 2007

1941 Giacomo Corneo and Olivier Jeanne, A Theory of Tolerance, March 2007

1942 Qing Hong and Michael Smart, In Praise of Tax Havens: International Tax Planning and Foreign Direct Investment, March 2007

1943 Yin-Wong Cheung, Dickson Tam and Matthew S. Yiu, Does the Chinese Interest Rate Follow the US Interest Rate?, March 2007

1944 Panu Poutvaara and Mikael Priks, Unemployment and Gang Crime: Could Prosperity Backfire?, March 2007

1945 Burkhard Heer, On the Modeling of the Income Distribution Business Cycle Dynamics, March 2007

1946 Christoph A. Schaltegger and Lars P. Feld, Are Fiscal Adjustments less Successful in Decentralized Governments?, March 2007

1947 Giovanni Facchini, Marcelo Olarreaga, Peri Silva and Gerald Willmann, Substitutability and Protectionism: Latin America's Trade Policy and Imports from China and India, March 2007 
1948 C. Mirjam van Praag and Bernard M. S. van Praag, The Benefits of Being Economics Professor A (and not Z), March 2007

1949 Astrid Hopfensitz and Frans van Winden, Dynamic Choice, Independence and Emotions, March 2007

1950 Guglielmo Maria Caporale and Luis A. Gil-Alana, A Multivariate Long-Memory Model with Structural Breaks, March 2007

1951 Mattias Ganslandt and Keith E. Maskus, Wholesale Price Discrimination and Parallel Imports, March 2007

1952 Michela Redoano, Fiscal Interactions Among European Countries. Does the EU Matter?, March 2007

1953 Stefan C. Wolter, Rémy Hübschi and Matthias Müller, Push or Pull? An Empirical Analysis of the Demand for Individual Project Grants from the Swiss National Science Foundation, March 2007

1954 Scott Alan Carson, African-American and White Inequality in the American South: Evidence from the $19^{\text {th }}$ Century Missouri State Prison, March 2007

1955 Peter Egger, Marko Koethenbuerger and Michael Smart, Do Fiscal Transfers Alleviate Business Tax Competition? Evidence from Germany, March 2007

1956 Panu Poutvaara and Lars-H. R. Siemers, Smoking and Social Interaction, March 2007

1957 Stephan Danninger and Fred Joutz, What Explains Germany’s Rebounding Export Market Share?, March 2007

1958 Stefan Krasa and Mattias Polborn, Majority-efficiency and Competition-efficiency in a Binary Policy Model, March 2007

1959 Thiess Buettner and Georg Wamser, Intercompany Loans and Profit Shifting Evidence from Company-Level Data, March 2007

1960 Per Pettersson-Lidbom and Mikael Priks, Behavior under Social Pressure: Empty Italian Stadiums and Referee Bias, April 2007

1961 Balázs Égert and Carol S. Leonard, Dutch Disease Scare in Kazakhstan: Is it real?, April 2007

1962 Paul De Grauwe and Pablo Rovira Kaltwasser, Modeling Optimism and Pessimism in the Foreign Exchange Market, April 2007 